\title{
Perinatal health care in a conflict-affected setting: evaluation of health-care services and newborn outcomes at a regional medical centre in Iraq
}

F.A.B. Ahamadani, ${ }^{1}$ H. Louis, ${ }^{2}$ P. Ugwi, ${ }^{2}$ R. Hines, ${ }^{2}$ M. Pomerleau, ${ }^{3}$ R. Ahn, ${ }^{2,4}$ T.F. Burke ${ }^{2,4}$ and B.D. Nelson ${ }^{2,4,5}$

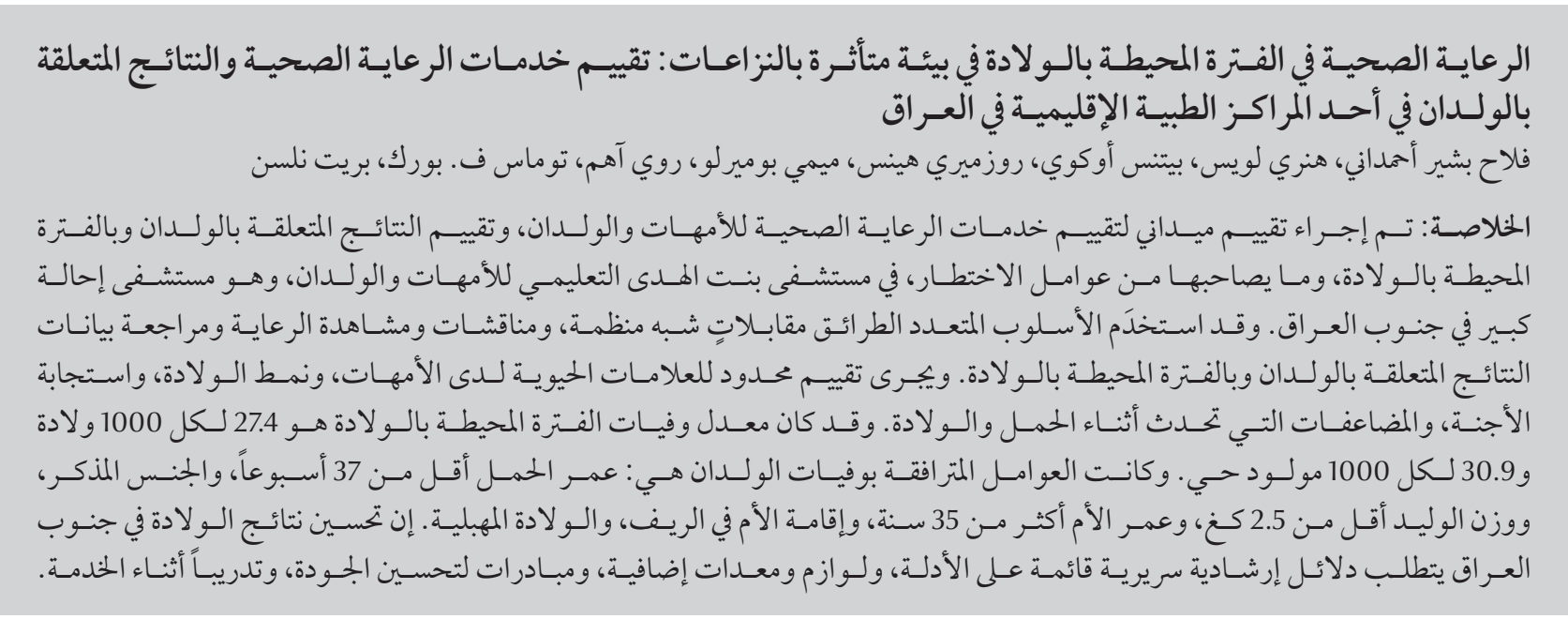

ABSTRACT A field-based assessment was conducted to assess maternal and newborn health-care services, perinatal and newborn outcomes and associated risk factors at Bint Al-Huda Maternal and Newborn Teaching Hospital, a large referral hospital in southern Iraq. The multi-method approach used interviews, discussions, observation and review of perinatal and newborn outcome data. There is limited assessment of maternal vital signs, labour pattern, fetal response, and complications during pregnancy and labour. Perinatal and neonatal mortality rates are 27.4/1000 births and 30.9/1000 live births respectively. Associated neonatal mortality factors were gestational age $<37$ weeks, male sex, birth weight $<2.5 \mathrm{~kg}$, maternal age $>35$ years, rural maternal residence and vaginal delivery. Improving birth outcomes in southern Iraq requires evidence-based clinical guidelines, additional supplies and equipment, quality improvement initiatives and in-service training.

Soins de santé périnatals dans un environnement de conflit : évaluation des services de soins de santé et des issues néonatales dans un centre médical régional en Iraq

RÉSUMÉ Une évaluation sur le terrain a été menée afin d'analyser les services de soins de santé pour la mère et le nouveau-né, les issues périnatales et néonatales et les facteurs de risque associés au centre hospitalier universitaire pour la mère et l'enfant Bint Al-Huda, un grand hôpital de recours dans le sud de l'Iraq. L'approche reposait sur de multiples méthodes et a eu recours à des entretiens semi-structurés avec des informateurs clés, à des petits groupes de discussion, à l'observation de la pratique des soins et à l'examen des données concernant l'issue des soins périnatals et néonatals. Les signes vitaux chez la mère, le déroulement du travail, la réponse foetale et les complications pendant la grossesse et le travail sont peu évalués. Les taux de mortalité périnatale et néonatale sont de 27,4/1000 naissances et de 30,9/1000 naissances vivantes respectivement ; les facteurs de mortalité néonatale associés étaient un âge gestationnel inférieur à 37 semaines, le sexe masculin, un poids de naissance inférieur à 2,5 kg, l'âge de la mère supérieur à 35 ans, un lieu de résidence rural, et un accouchement par voie basse. L'amélioration des issues néonatales dans le sud de l'Iraq passe par des recommandations cliniques fondées sur des bases factuelles, des fournitures et des équipements supplémentaires, des initiatives visant à améliorer la qualité et des formations en cours d'emploi.

'Bint Al-Huda Maternal and Child Teaching Hospital, Dhi Qar Governorate, Nasiriyah, Iraq. ${ }^{2}$ Division of Global Health and Human Rights, Department of Emergency Medicine, Massachusetts General Hospital, Boston, Massachusetts, USA. ${ }^{3} \mathrm{MGH}$ Institute of Health Professionals, Boston, Massachusetts, USA. ${ }^{4}$ Harvard Medical School, Boston, Massachusetts, USA. ${ }^{5}$ Division of Global Health, Department of Pediatrics, Massachusetts General Hospital, Boston, Massachusetts, USA (Correspondence to B.D. Nelson: brett.d.nelson@gmail.com).

Received: 03/06/14; accepted: 14/10/14 


\section{Introduction}

Maternal and newborn health-care systems throughout the world have been severely disrupted by conflict and social unrest, and many of these systems share common needs and barriers to their development and recovery. The healthcare system in Iraq — previously among the very best in the Middle East - has been severely weakened over the last couple of decades (1). For the last 2 decades, severe cuts in public health spending and years of conflict and occupation have left the health infrastructure of the country fragile and inadequate. The effects have been especially devastating for women and children, with routine immunizations reduced, pregnant women unable to reach hospitals for delivery and essential medical supplies limited (2,3). Southern Iraq has been particularly affected, with some of the worst maternal, newborn and child health indicators in Iraq and among surrounding countries (4).

However, with the hope for increasing peace and stability in Iraq, greater attention has been paid in recent years to improving the health of the Iraqi people. Many of the health needs in southern Iraq are addressed by the Bint Al-Huda Maternity and Child Teaching Hospital, located in Nasiriyah, the capital of the Dhi Qar Province. This is a large 300-bed tertiary referral hospital that provides maternal and newborn care to its catchment population of 2.5 million people. It is a very active teaching hospital with roughly $20000-25000$ deliveries a year (or approximately 60-80 deliveries per day, many of which are surgical). Despite the high volume of births, a thorough understanding of maternal and newborn health-care needs is lacking and capabilities in the hospital are limited.

To elucidate these needs and capabilities, we conducted a field-based needs assessment of current maternal and newborn health-care services at Bint Al-Huda Maternity and Child Teaching
Hospital. Furthermore, through extensive data collection, we evaluated perinatal and neonatal outcomes and associated risk factors among births at the hospital. Our ultimate goal was to provide local policy-makers and other stakeholders with informed, actionable recommendations for further improving maternal and newborn care. The assessment may also offer lessons regarding strengthening health systems in post-conflict settings throughout the world, including regional health systems and those in countries emerging from the so-called Arab Spring popular uprisings.

\section{Methods}

\section{Study design and setting}

In partnership with the Bint Al-Huda Maternity and Child Teaching Hospital, the Ministry of Health and the International Children's Heart Foundation, our clinician research team from Massachusetts General Hospital, Boston, United States of America conducted a field-based maternal and newborn health-care needs assessment among providers and administrators at Bint Al-Huda Hospital. In August 2013, our team travelled to Nasiriyah and conducted semi-structured key-informant interviews, small-group discussions and direct observation of maternal and newborn care. Participants included local clinicians and administrators. Verbal informed consent was obtained from all participants before inclusion in the project.

This project was undertaken as a quality improvement initiative at Bint Al-Huda Hospital and, as such, was not formally supervised by the institutional review board as per their policies. Similarly, the partners' human research committee (Massachusetts General Hospital, Boston) reviewed the project and found ethical approval not applicable owing to its quality improvement nature.

\section{Data collection}

The interviews and small-group discussions consisted of open-response questions related to health-care services, providers, equipment, supplies and medications. Other questions included the most common clinical presentations of patients presenting for care, the continuing medical education needs of staff and other recommendations for improving patient care.

Additionally, we collected data on all newborns born at the hospital during the preceding year (1 January 2012 to 31 December 2012) to gain a representative understanding of perinatal and newborn outcomes in the region. Data collected from death certificates, delivery registers and unit registers were used to determine the number of perinatal deaths; number of neonatal deaths; perinatal mortality rate; neonatal mortality rate; potential risk factors, such as birth weight or sex; and the leading causes of death.

\section{Data analysis}

The interview responses and birth data were analysed using standard statistical methods. The 2 lead field researchers conducted initial theme analysis of the detailed assessment field notes, which were reviewed and clarified by consensus with the larger research team. Descriptive statistics with frequencies and rates were prepared using Microsoft Excel 2010. To determine the associated risk factors for mortality [odds ratio (OR) and 95\% confidence interval (CI)] and their statistical significance, logistic regression was performed using MedCalc, version 12.7.8.

\section{Results}

\section{Maternal and newborn health- care needs assessment}

Bint Al-Huda Maternity and Child Teaching Hospital provides maternal and newborn health-care services to the 
2.5 million people in the community of Nasiriyah and surrounding areas. It also serves as the referral centre for 4 other hospitals in the region.

The 300-bed hospital includes 120 newborn/paediatric beds, 180 obstetric beds, emergency room for paediatric patients ( 30 beds, 4 of which are monitored), 2 operating theatres, an antenatal care clinic, a labour and delivery suite with 2 labour rooms and 8 total delivery beds, newborn resuscitation areas between the 2 delivery rooms (with 2 radiant warmer beds) and adjacent to the 2 operating theatres (with 4 radiant warmer beds), post-anaesthesia care unit, 2 postpartum units ( 32 beds total) ( 1 unit with private rooms and 1 unit with multiple-bed rooms).

There are a total of 18 paediatricians on a rotating schedule that covers the paediatric and neonatal service, including 3 senior attending-level paediatricians, 5 paediatric fellows and 10 paediatric residents (each on a 3-month paediatric rotation). For obstetrics, there are 2 senior attending-level obstetrician-gynaecologists and currently 1 visiting obstetrician-gynaecologist, who assists with the large number of caesarean sections performed at the hospital. Obstetric residents provide a large bulk of the obstetric care, including 2 residents who triage and support the labour and delivery unit.

In the labour ward, there is a $1: 4$ nurse to patient ratio, and during delivery the ratio is $1: 1$. During uncomplicated vaginal deliveries, nurses are the primary provider, with physicians supervising and assisting with high-risk deliveries and complications. Nurses do not assess labour patterns, fetal status or collect patient vital signs. Nurses work on a schedule of 24 hours on and 48 hours off. The reported level of nursing skills varies widely; some nurses have no formal training, some have completed a diploma-type programme and few have completed a baccalaureate degree. After an unexpected outcome (e.g. neonatal death, maternal complications) there is no routine debriefing, root-cause analysis or quality improvement initiatives for the purpose of performance improvement in the future.

Bint Al-Huda Hospital is fairly wellequipped with the essential supplies for newborn and maternal health. There are 18 incubators in the inborn newborn units and an additional 30 incubators for newborns born outside the hospital and admitted to Bint Al-Huda. The hospital has a Doppler machine to assess fetal heart rate (used only by physicians) and an electronic fetal heart monitor (used for fetal heart assessment but not for uterine contractions).

The hospital has a limited supply of bag-mask devices and bulb suctions in the newborn resuscitation areas, and it appears these are used infrequently. Currently, the hospital uses deep suctioning with wall-mounted suction catheters for newborns. Only 2 of the 6 warmers had a functioning heat source. The hospital does not have sufficient supplies of alcohol wipes, equipment sanitizing wipes, IV pumps, absorbent towels for drying newborns after delivery, blankets for swaddling newborns or sheets or pillows for labouring mothers. There is regular doubling of patients, with mothers sharing labour beds and newborns sharing cribs and warmers.

Assessment and documentation of maternal vital signs, labour pattern, fetal response, and complications during pregnancy and labour is scarce. The World Health Organization (WHO) modified partograph was recently introduced, but its use remains sporadic. Physicians are the only clinical staff members who obtain vital signs, monitor labour and monitor fetal response to labour. There is minimal personnel support for women in labour.

Following birth, newborns are usually separated from their mothers for more than 30 minutes. There is no skin-to-skin care. Following uncomplicated vaginal deliveries, mothers and their newborns remain in the hospital only 4 hours due to space constraints. After caesarean section delivery, they stay 2 days. There is no consistent change of bed coverings, hand washing or changing of gloves between patients.

The hospital provided 24909 deliveries during the study year, or a mean of 68.2 deliveries/day. The monthly caesarean section rate is reportedly $40-60 \%$, which is well above the WHO recommended rate of $10-15 \%$ (5). Although the high rate at this hospital was reported to be due in part to its role as a tertiary referral centre for higher-risk pregnancies, it was also attributed to lack of training in appropriate management and to a high staff workload.

The vast majority of deliveries in the Nasiriyah community are facility-based deliveries occurring at Bint Al-Huda Hospital, the only referral centre in the region. An estimated $5-10 \%$ of deliveries may occur outside of facilities among traditional birth attendants, community midwives and/or family members. Staff reported that reasons for non-facility-based deliveries include limited access in rural areas, transport costs (even though hospital care is free) and cultural beliefs. Staff believe however, that the community typically trusts and respects the hospital. Within the greater Dhi Qar Province, for which Nasiriyah is the capital, there were 65699 births during the same time period, with $27.4 \%$ of the provincial deliveries occurring at Bint Al-Huda Hospital. Nevertheless, within Nasiriyah, a large majority of both high-risk and normal-risk deliveries reportedly occur at the hospital.

\section{Peri- and neonatal mortality rates and associated factors}

Among the 24909 births analysed in the study, the total number of perinatal deaths (stillbirths and deaths within the 1 st 6 days of life) was 683 , 
with 114 stillbirths and 569 neonatal deaths occurring in the 1st week of life (Table 1 ). As a result, the perinatal mortality rate (stillbirths and early neonatal deaths) was 27.4 per 1000 total births.

The total number of neonatal deaths (deaths occurring within the first 28 days of life) was 766 , with 569 deaths occurring in the 1st week of life and 197 deaths occurring between the 7 th and 28th day after birth. The neonatal mortality rate (NMR) was therefore 30.9 per 1000 live births

The leading causes of death were respiratory distress (34.1\%), prematurity $(24.3 \%)$ and birth asphyxia (20.6\%).

The demographic data of all live births $(n=24795)$ at Bint Al-Huda Maternity and Child Teaching Hospital in 2012 are shown in Table 2.

Male neonates had a higher NMR (39.1/1000 live births) compared with female neonates (23.0/1000 live births) $(P<0.001)$ (Table 3). There were 2315 (9.1\%) low-birth-weight babies, and the average NMR for this group (258.4/1000 live births) was higher than the NMR for the normal-weight babies (16.3/1000 live births) $(P<$ 0.001).

Using logistic regression, the associated risk factors for NMR were gestational age $<37$ weeks (OR 19.4; 95\% CI: 16.7-22.9), male sex (OR 1.70; 95\% CI: 1.46-1.96), neonatal weight < $2.5 \mathrm{~kg}$ (OR 12.5; 95\% CI: 10.8-14.6), mother's age $>35$ years (OR 1.50; $95 \%$ CI: 1.21-1.86), mother's residence in a rural area (OR 1.17; 95\% CI: 1.01$1.35)$, and vaginal mode of delivery (OR 1.67; 95\% CI: 1.44-1.94). There was no significant association between NMR and antenatal care (OR 1.23; 95\% CI: 0.96-1.56) and mother's age < 18 years (OR 1.38; $95 \%$ CI: 0.99-1.92) (Table 4). Regression analysis was not conducted on the 114 stillbirths as demographic data were not available in the database.

\begin{tabular}{|c|c|c|}
\hline Variable & No. of births & $\%$ \\
\hline \multicolumn{3}{|l|}{ Perinatal deaths } \\
\hline Stillbirths & 114 & 16.7 \\
\hline Early neonatal deaths (day 1-6) & 569 & 83.3 \\
\hline Total perinatal deaths & 683 & 100.0 \\
\hline \multicolumn{3}{|l|}{ Neonatal deaths } \\
\hline Early neonatal deaths (day 1-6) & 569 & 74.3 \\
\hline Late neonatal deaths (day 7-28) & 197 & 25.7 \\
\hline Total neonatal deaths (day 1-28) & 766 & 100.0 \\
\hline \multicolumn{3}{|l|}{ Causes of neonatal mortality } \\
\hline Respiratory distress & 261 & 34.1 \\
\hline Prematurity & 186 & 24.3 \\
\hline Asphyxia & 158 & 20.6 \\
\hline Sepsis & 63 & 8.2 \\
\hline Congenital anomalies & 31 & 4.0 \\
\hline Congenital pneumonia & 10 & 1.3 \\
\hline Unknown & 57 & 7.4 \\
\hline
\end{tabular}

Table 2 Demographic data of all live births at Bint Al-Huda Maternity and Child Teaching Hospital, Nasiriyah, southern Iraq, 2012 ( $n=24795$ infants)

\begin{tabular}{|c|c|c|}
\hline Variables & No. of births & $\%$ \\
\hline \multicolumn{3}{|l|}{ Birth weight (kg) } \\
\hline$<1.5$ & 361 & 1.5 \\
\hline $1.5-<2$ & 527 & 2.1 \\
\hline $2-<2.5$ & 1034 & 4.2 \\
\hline$\geq 2.5$ & 22873 & 92.2 \\
\hline \multicolumn{3}{|c|}{ Gestational age (weeks) } \\
\hline$<37$ & 2402 & 9.7 \\
\hline$\geq 37$ & 22393 & 90.3 \\
\hline \multicolumn{3}{|l|}{ Sex } \\
\hline Female & 12609 & 50.9 \\
\hline Male & 12186 & 49.1 \\
\hline \multicolumn{3}{|l|}{ Mother's age (years) } \\
\hline$\leq 18$ & 946 & 3.8 \\
\hline $19-35$ & 21467 & 86.6 \\
\hline$\geq 36$ & 2382 & 9.6 \\
\hline \multicolumn{3}{|c|}{ Mother received antenatal care } \\
\hline Yes & 22752 & 91.8 \\
\hline No & 2043 & 8.2 \\
\hline \multicolumn{3}{|l|}{ Mother's residence } \\
\hline Rural & 14321 & 57.8 \\
\hline Urban & 10474 & 42.2 \\
\hline \multicolumn{3}{|l|}{ Mode of delivery } \\
\hline Vaginal delivery & 13233 & 53.4 \\
\hline Caesarean section & 11562 & 46.6 \\
\hline
\end{tabular}




\section{Discussion}

After decades of conflict and sociopolitical disruption, Iraq's health services remain fractured and fragile. Efforts are underway to restore what was once among the best health-care systems in the region, but significant work is still needed, especially in southern Iraq, which has historically been overlooked. With a catchment population of 2.5 million and at least 20000 deliveries per year, the Bintu Al-Huda Hospital is a key site of maternal and newborn care in southern Iraq. Our study illustrates the many challenges in providing essential newborn and maternal health care in a country recovering from years of instability and conflict.

At 30.9 deaths per 1000 total live births, the neonatal mortality rate is high, with low-birth-weight neonates and male neonates at highest risk for death. The mortality rate is much higher than that of Iraq as a whole (20/1000 live births) and is significantly higher than the rates in many surrounding countries in the Eastern Mediterranean Region (6).

At Bint Al-Huda Hospital, there is a clear need for additional supplies to increase the safety and cleanliness of labour and delivery. In the newborn resuscitation areas, additional bag-mask devices, bulb suctions and a functioning heat source for the warmers could potentially prevent a number of neonatal deaths. Deep suctioning with a suction catheter should only be done rarely, as it can cause a vasovagal reflex that reduces the newborn's heart rate and respiratory rate. There is currently no continuous positive airway pressure (CPAP) machine, which could be a useful and, in the case of bubble CPAP, is a very simple intervention to reduce newborn morbidity and mortality due to respiratory complications. Additionally, infections could be reduced with improved clean birth practices, greater infection control and increased number of labour beds and cribs to minimize

\begin{tabular}{|c|c|c|}
\hline Variable & $\begin{array}{c}\text { NMR } \\
\text { (per } 1000 \text { live births) }\end{array}$ & $P$-value \\
\hline Total & 30.9 & \\
\hline \multicolumn{3}{|c|}{ Gestational age (weeks) } \\
\hline$<37$ & 216.6 & $<0.001$ \\
\hline$\geq 37$ & 11.0 & \\
\hline \multicolumn{3}{|l|}{ Sex } \\
\hline Female & 23.0 & $<0.001$ \\
\hline Male & 39.1 & \\
\hline \multicolumn{3}{|l|}{ Neonatal weight $(\mathrm{kg})$} \\
\hline$<1.5$ & 465.4 & \\
\hline $1.5^{-<2}$ & 187.8 & $<0.001$ \\
\hline $2-<2.5$ & 121.9 & \\
\hline$\geq 2.5$ & 16.3 & \\
\hline \multicolumn{3}{|l|}{ Mother's age (years) } \\
\hline$\leq 18$ & 40.1 & \\
\hline $19-35$ & 29.1 & $<0.001$ \\
\hline$\geq 36$ & 43.7 & \\
\hline \multicolumn{3}{|l|}{ Antenatal care } \\
\hline Yes & 30.3 & 0.110 \\
\hline No & 37.2 & \\
\hline \multicolumn{3}{|l|}{ Mother's residence } \\
\hline Rural & 32.9 & 0.043 \\
\hline Urban & 28.2 & \\
\hline \multicolumn{3}{|l|}{ Mode of delivery } \\
\hline Vaginal delivery & 38.0 & $<0.001$ \\
\hline Caesarean section & 22.7 & \\
\hline
\end{tabular}

the number of patients sharing space (7-11).

There was an evident need and desire for additional staff training among providers in the hospital. As a teaching institution, with rotating students and trainees, there is a strong interest in education and a commitment to improving the capacity of the hospital to provide high-quality care to women and children in the Nasiriyah region. Our assessment showed that training topics should include basic sanitary practice and infection control, basic emergency obstetric and newborn care (e.g. the BEmONC project), essential newborn care, newborn resuscitation (e.g. the Helping Babies Breathe programme, Newborn Resuscitation Programme), setting-appropriate intensive newborn care (e.g. the STABLE programme) and others. Staff should be trained in evidence-based clinical guidelines, such as indications for caesarean section, triage, danger signs, etc., and these should be posted at all points of care for convenient and frequent reference by providers. Once essential care has been effectively established, the focus can shift towards rebuilding advanced critical care services. As a teaching and referral centre, Bint Al-Huda Hospital should also continue to help build capacity among lower-level referring facilities in the region.

Additionally, routine debriefing and root-cause analysis among providers should be in place to improve future 


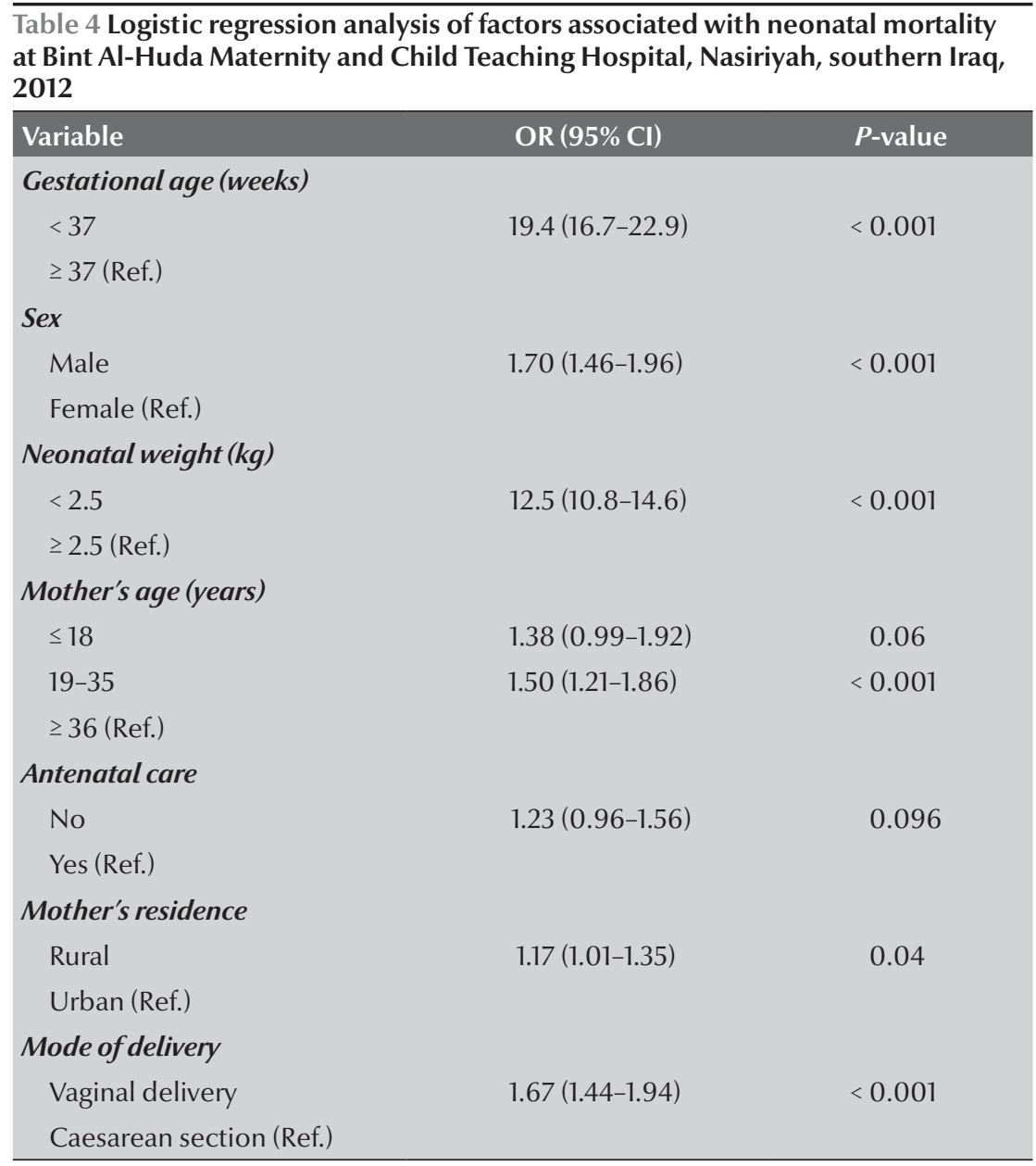

$O R=$ odds ratio $; C I=$ confidence interval $;($ Ref. $)=$ reference category.

performance $(12,13)$. Quality improvement initiatives should be introduced and these should have strong local ownership (14). This approach would, ideally, facilitate staff-led identification of improvement priorities, development of setting-appropriate solutions, regular monitoring of progress towards clearly delineated goals, as well as any needed course corrections (15).

Overall, this study may provide valuable lessons for Iraq and for other conflict-affected regions that will need to reconstruct health systems and build indigenous health-care capacity. While addressing problems in the physical infrastructure of hospitals is an important facet of reconstruction, so too is the need to strengthen hospital management systems; ensure appropriate stocks of supplies, medications and medical equipment are requested from the Ministry of Health; implement quality improvement initiatives; and provide clinical staff with continuing education and training on evidence-based care to ensure the provision of quality health services (16). Subsequent to this evaluation, many of these proposals are now under way at Bint Al-Huda Hospital.

This study had some limitations. The interviews and data collection did not go beyond Bint Al-Huda Hospital. The mortality statistics and risk factors were limited to facility-based deliveries at the hospital. Because it serves as a referral centre, this hospital may have higher mortality rates as a consequence of serving generally higher-risk patients. However, this teaching hospital provides the vast majority of coverage in its community for both high-risk and normal-risk deliveries, and we believe that the numbers are a good representation of the region as a whole. The survey involved hospital providers, administrators and staff; it did not include direct assessment of patients or community perceptions. Another limitation of the study is a result of the existing health information system. Our available datasets involved monthly collated data rather than disaggregated data. Consequently, some descriptive results were not available, such as standard deviation. Stillbirth data did not include gestational age, weight and other descriptors and this prevented additional analysis.

In conclusion, improving maternal and birth outcomes in southern Iraq requires a collaborative effort to ensure quality maternal and newborn services. Improvement will require implementing additional evidencebased clinical guidelines, investing in supplies and equipment, establishing quality improvement initiatives and introducing regular in-service training and support. Currently identified training needs include intrapartum monitoring and care, newborn resuscitation, essential newborn care and infection control.

Funding: Iraq Regional Ministry of Health and the International Children's Heart Foundation.

Competing interests: None declared.

\section{References}

1. Al Hilfi TK, Lafta R, Burnham G. Health services in Iraq. Lancet. 2013 Mar 16;381(9870):939-48. PMID:23499042

2. Webster P. Reconstruction efforts in Iraq failing health care. Lancet. 2009 Feb 21;373(9664):617-20. PMID:19238694
3. Webster PC. Iraq's health system yet to heal from ravages of war. Lancet. 2011 Sep 3;378(9794):863-6. PMID:21898919

4. Valenciano M, Coulombier D, Lopes Cardozo B, Colombo A, Alla MJ, Samson S, et al. Challenges for communicable disease 
surveillance and control in southern Iraq, April-June 2003. JAMA. 2003 Aug 6;290(5):654-8. PMID:12902370

5. Gibbons L, Belizan JM, Lauer JA, et al. The global numbers and costs of additionally needed and unnecessary caesarean sections performed per year: overuse as a barrier to universal coverage. Geneva: World Health Organization; 2010 (World Health Report Background Paper No. 30).

6. The state of the world's children. Geneva: United Nations Children's Fund; 2011 (http://data.un.org/Data. aspx?d=SOWC\&f=inID\%3A145\#SOWC, accessed 6 September 2014).

7. Singh S, Kumar RK, Sundaram KR, Kanjilal B, Nair P. Improving outcomes and reducing costs by modular training in infection control in a resource-limited setting. Int J Qual Health Care. 2012 Dec;24(6):641-8. PMID:23074181

8. Allegranzi B, Pittet D. Healthcare-associated infection in developing countries: simple solutions to meet complex challenges. Infect Control Hosp Epidemiol. 2007 Dec;28(12):1323-7. PMID:17994510

9. Pittet D, Allegranzi B, Storr J. The WHO Clean Care is Safer Care programme: field-testing to enhance sustainability and spread of hand hygiene improvements. J Infect Public Health. 2008;1(1):4-10. PMID:20701840

10. Core components for infection prevention and control programmes: report of the Second Meeting Informal Network on Infection Prevention and Control in Health Care. Geneva: World Health Organization; 2009 (http://apps.who.int/medicinedocs/documents/s16342e/s16342e.pdf, accessed 6 September 2014).
11. Essential environmental health standards in health care. Geneva: World Health Organization; 2008 (http://www.who.int/ water_sanitation_health/hygiene/settings/ehs_health_care. pdf.pdf, accessed 6 September 2014).

12. WHO draft guidelines for adverse event reporting and learning systems. Geneva: World Health Organization; 2005 (http:// www.who.int/patientsafety/events/05/Reporting_Guidelines. pdf, accessed 6 September 2014).

13. Le Duff F, Daniel S, Kamendjé B, Le Beux P, Duvauferrier R. Monitoring incident report in the healthcare process to improve quality in hospitals. Int J Med Inform. 2005 Mar;74(24):111-7. PMID:15694615

14. Øvretveit J. Formulating a health quality improvement strategy for a developing country. Int J Health Care Qual Assur Inc Leadersh Health Serv. 2004;17(7):368-76. PMID:15552392

15. Massoud R, Askov K, Reinke J, Franco LM, Bornstein T, Knebel E, MacAulay C. A modern paradigm for improving healthcare quality. Bethesda, Maryland: The Quality Assurance Project, for the United States Agency for International Development; 2001 (QA Monograph Series 1) (http://nationalqualitycenter.org/download_resource.cfm?fileID=16656, accessed 6 September 2014).

16. The Partnership for Maternal, Newborn, and Child Health. Essential Interventions, Commodities and Guidelines for Reproductive, Maternal, Newborn and Child Health: a global review of the key interventions related to reproductive, maternal, newborn and child Health. Geneva: The Partnership for Maternal, Newborn, and Child Health; 2011 (http://www. who.int/pmnch/topics/part_publications/essential_interventions_18_01_2012.pdf?ua=1, accessed 6 September 2014). 